\title{
A indissociabilidade entre inclusão digital e software livre na sociedade contemporânea: a experiência do mutirão pela inclusão digital *
}

\author{
Adriano Canabarro Teixeira \\ Aline de Campos
}

\begin{abstract}
Resumo - Na Sociedade Contemporânea, profundamente modificada pelo advento das Tecnologias de Rede, um processo específico de exclusão têm se apresentado como determinante para a manutenção dos papéis sociais, aquele que não inviabiliza o acesso às tais tecnologias, mas que determina diferentes formas de acesso para as diversas camadas sociais. Assim, a partir destas reflexões se propõe a necessária ampliação do conceito de Inclusão Digital e se reflete sobre sua indissociável ligação com Software Livre e a filosofia que o fundamenta, elementos que serviram de base para o relato da experiência do primeiro grupo de alunos no projeto Mutirão pela Inclusão Digital, proposto e realizado pelo Curso de Ciência da Computação da Universidade de Passo Fundo em parceria com o Centro de Referência em Literatura e Multimeios no ano de 2004.
\end{abstract}

Palavras-Chave - Software Livre, Inclusão Digital e Sociedade Contemporânea.

Abstract - In the Contemporary Society, deeply modified for the advent of the Technologies of Net, a specific process of exclusion has presented as determinative for the maintenance of the social papers, that one that does not make impracticable the access to such technologies, but determines different forms of access for the diverse social classes. Thus, based on these reflections one proposes the necessary increase of the concept of Digital Inclusion and reflects on its indivisible linking with Free Software and the philosophy that bases on it, elements that had served of base for the story of the experience of the first group of students in the "Mutirão" project for the Digital Inclusion, proposed and carried out by the Course of Computer science of the University of Passo Fundo in partnership with the Center of Reference in Literature and Multimedia in the year of 2004.

Key words - Free software, Digital Inclusion and Contemporary Society.

\section{COMPONDO A TRAMA INICIAL}

Antes de relatar a experiência realizada no Mutirão pela Inclusão Digital e de realizar reflexões acerca desta iniciativa, é oportuno que se reconstrua a rede de sentidos e conceitos a partir da qual tal proposta foi delineada e que também servirá de base para a compreensão da dinâmica inerente ao processo e das concepções que o permeiam. Dentre os nós constituintes desta trama destacam-se os seguintes:

\footnotetext{
Artigo apresentado como pôster no VII Simpósio Internacional de Informática Educativa. Referência completa: TEIXEIRA, Adriano Canabarro. A indissociabilidade entre Inclusão Digital e Software Livre na Sociedade Contemporânea: a experiência do Mutirão pela Inclusão Digital. Pôster in: VII Simpósio Internacional de Informática Educativa, 2005b, Leiria, Portugal. Anais do SIIE 2005.

... Professor pesquisador da Universidade de Passo Fundo, mestre em educação - teixeira@upf.br.

Bolsista de iniciação científica da Universidade de Passo Fundo - 55585@inf.upf.br

V.3 $\mathrm{N}^{\circ} 2$, Novembro, 2005
} 
(1) a necessidade de ampliação do conceito de inclusão digital e de suas implicações em uma sociedade profundamente modificada pela presença das Tecnologias de Rede TR; e

(2) o fenômeno do Software Livre como representação de um novo paradigma de construção e de difusão do conhecimento, especialmente a partir do contexto brasileiro e como ponto chave para a construção de processos de inclusão digital que considerem não somente a utilização desta modalidade de software, mas principalmente sua filosofia em uma dinâmica de valorização cultural e de respeito às demais através de experiências de autoria e co-autoria.

\section{CONECTANDO ALGUNS NÓS DA REDE}

Baseadas na lógica das redes, as TR possuem características que as diferenciam das tecnologias baseadas na configuração Um para Todos, a medida em que possibilitam, e exigem, o estabelecimento de processos de comunicação bidirecional fundados na troca e na colaboração.

Tais características subvertem a perspectiva de passividade e de reprodução dos massmedia, uma vez que instauram uma organização comunicacional do tipo Todos para Todos, possibilitando que cada indivíduo seja um nó ativo da rede de sentidos, requisito básico para que possa fazer parte daquilo que Lemos caracteriza como "o novo espaço sagrado contemporâneo" (2002, p. 142), o Ciberespaço.

Instituído a partir do anulamento das distâncias pelo Tempo Real conseqüente das TR, o ciberespaço constrói-se como o novo local de exercício e desenvolvimento da cidadania na sociedade atual, que, a partir da libertação dos limites geográficos e temporais, desvincula presença física de presença potencial, ampliando a área de ação dos indivíduos e aproximando de forma inédita, culturas, costumes e interesses.

Referindo-se às modificações conseqüentes deste conceito de tempo, Santos afirma que "autoriza usar o mesmo momento a partir de múltiplos lugares; e todos os lugares a partir de um só deles" (2004, p. 28), ampliando desta forma o campo de ação e de presença dos indivíduos que, independente de onde estejam fisicamente, vivem uma realidade em que assumem o status de possíveis emissores em estado de permanente recepção.

Desta forma, esta condição de potencial onipresença do homem moderno, traz em si um elemento a ser considerado seriamente: a possibilidade de estabelecimento e de ampliação de relações de dominação e imposição sócio-cultural. Tal perigo é destacado por Serpa quando alerta que "o novo poder hegemônico [...] utiliza a espacialização do tempo como estrutura de expansão política e ideológica e coloca-se como centro do espaço sincronizado" (2004, p. 155), o que contraria a dinâmica das redes caracterizada pela ausência de um nodo central, "ao mesmo tempo, mantém a inclusão do Outro somente como consumidor".

Associa-se esta afirmação, à detecção de um movimento por parte do mercado no sentido de anular as características reticulares das tecnologias contemporâneas utilizando-as como Tecnologias de Acesso e não mais como Tecnologias Comunicacionais, mantendo a tradicional lógica broadcast, e, desta forma, reforçando a passividade e manutenção da hegemonia impostas pela condição de recepção.

A Inclusão Digital e a urgência de (re) significação.

Feitas estas considerações, é preciso reconhecer a necessidade de reflexões a cerca da concepção de Inclusão Digital que, a partir do paradigma das redes, é contrária a idéia amplamente difundida de que incluir digitalmente é uma questão de possibilitar o acesso às TR a determinadas camadas da sociedade, pois, uma vez assumindo este discurso, ignora-se as potencialidades altamente revolucionárias e libertadoras destas tecnologias 
que "oferecem a possibilidade de superação do imperativo da tecnologia hegemônica e paralelamente admitem a proliferação de novos arranjos, com a retomada da criatividade". (SANTOS, 2004, p. 81).

A partir da superação da concepção de Inclusão Digital enquanto acesso, pode-se afirmar que, não somente as camadas já excluídas economicamente necessitam vivenciar momentos de (re) apropriação crítica das TR, mas uma parcela muito maior da sociedade que, ainda imersa em uma utilização passiva das tecnologias contemporâneas às utiliza em uma perspectiva linear, verticalizada e hierarquizada, em uma dinâmica de passividade e recepção, garantindo desta forma a manutenção da organização social contemporânea essencialmente fundada no consumo e na reprodução.

Tal configuração, explicita a complexidade e a importância de apropriação das TR em uma perspectiva reticular, pois incluir digitalmente deixou de ser uma ação necessária para minimizar uma situação de seletividade específica contribuindo para a inclusão social, para assumir o papel de elemento fundamental e determinante para o desenvolvimento humano e social e para a inclusão dos sujeitos enquanto cidadãos.

Assim, Inclusão Digital implica reconhecer-se enquanto nó de uma rede de sentidos suportada pelas TR, a partir de uma apropriação crítica, provisória e reflexiva destes fenômenos técnicos, em uma dinâmica de (co) autoria, de partilha do conhecimento e de estabelecimento de processos colaborativos e comunicacionais, baseados no protagonismo, na valorização da própria cultura, no respeito à diversidade e na criação e manutenção de uma cultura de redes.

\section{O Software Livre como manifestação de Inclusão Digital}

A partir deste contexto, alguns elementos contemporâneos são extremamente significativos e não podem ser ignorados na medida em que expressam de forma profunda e extremamente contundente esta concepção de Inclusão Digital baseada na horizontalidade, na ação colaborativa e na livre construção e circulação do conhecimento, como, por exemplo, o fenômeno do Software Livre.

Mais do que uma alternativa técnica e economicamente viável, o Software Livre representa uma opção pela criação, pela colaboração e pela independência tecnológica e cultural, uma vez que é "baseado no princípio do compartilhamento do conhecimento e na solidariedade praticada pela inteligência coletiva conectada na rede mundial de computadores". (SILVEIRA, 2003, p. 36).

Tal entendimento, amplia a concepção de opção pela utilização de softwares nãoproprietários, para uma dimensão de apropriação da filosofia colaborativa, libertadora e inclusiva que fundamenta o Software Livre, enquanto elemento base para iniciativas de Inclusão.

Assim, aponta-se para a incoerência em se pensar inclusão digital feita com software proprietário, e se amplia a significação e a complexidade desta idéia afirmando que, tão importante quanto à utilização de Software Livre nestas iniciativas de inclusão, é a apropriação de sua filosofia, baseada na horizontalidade dos processos, no estabelecimento de parcerias criativas e no reconhecimento do potencial autoral de cada nó da rede.

Extremamente significativa, e ampliando ainda mais a íntima ligação entre Software Livre e iniciativas de Inclusão Digital especialmente no contexto brasileiro, a recente opção nacional pela utilização de Software Livre em todas as escolas e estabelecimentos públicos, também merece destaque como uma Política Pública que, mais do que efeitos econômicos, pode conduzir a mudanças culturais e ideológicas profundas, contribuindo para o rompimento com o poder simbólico situado no Mercado e que "desterritorializa o território nacional, produzindo uma configuração de não-lugares”. (SERPA, 2004, p. 
147). Entretanto, antes de tratar da questão a nível nacional é importante relatar alguns elementos do pioneirismo do Rio Grande do Sul na área.

No que se refere às iniciativas gaúchas, pode-se destacar a utilização de softwares livres nos serviços de auto-atendimento do Banco do Estado do Rio Grande do Sul Banrisul, que remonta ao ano 2000; o Fórum Internacional de Software Livre que teve sua primeira edição no mesmo ano; e o projeto Rede Escolar Livre que em 2001, mesmo em uma perspectiva inicial de inclusão enquanto acesso, já fazia a opção pela utilização de Softwares Livres em escolas estaduais do município de Porto Alegre.

Configurando-se como uma das primeiras migrações na área financeira a nível mundial, extremamente significativo em se tratando de uma área fundamental ao Mercado e rompendo com a hegemonia do software proprietário na área econômica, o Banrisul iniciou em 2000 a migração de seus computadores de auto-atendimento para o Sistema Operacional Linux, sendo que atualmente quase a totalidade de suas máquinas opera com este sistema. Segundo informações do Ministério de Ciência e Tecnologia, todos os 400 servidores do banco estatal gaúcho já operam com o Linux, assim como 3 mil das 4 mil estações de trabalho. (BRASIL, 2005).

O Fórum Internacional de Software Livre, cuja primeira edição remonta também ao ano 2000, é promovido pelo Projeto Software Livre RS e já realizou 6 edições, conhecido como o maior evento na área em nível mundial, seu objetivo é disseminar a idéia de utilização e desenvolvimento de software livre e promover a uma cultura baseada em sua filosofia e explicitamente representada no slogan de 2005: "Tecnologia que liberta".

Dentre os programas de inclusão digital da Prefeitura Municipal de Porto Alegre, alguns podem ser tomados como modelo. Dentre eles, o projeto "Informática na Educação: uma rede para inclusão digital", implantado na rede municipal de ensino da Prefeitura de Porto Alegre e que adota o Software Livre. Segundo informações do projeto (PROCEMPA, 2005), os ambientes informatizados das escolas já atendem 91,3\% dos alunos através de um sistema que interliga 51 redes locais de escolas de variadas regiões da cidade. A rede dispõe de sistema operacional Linux, com StarOffice, correio eletrônico e acesso à Internet.

Implantados como parte da política pedagógica, os ambientes informatizados são usados pelas diversas disciplinas para desenvolver seus conteúdos. O projeto, premiado nacionalmente, busca "romper a lógica de exclusão social, criando meios para apropriação de tecnologia da informação desde a escola" (2005), sendo que as 52 escolas dos níveis fundamental, médio e básico, já possuem ambientes informatizados, e a segunda fase do projeto está informatizando as 40 escolas de educação infantil da cidade, restando apenas quatro para a totalização do projeto de informatização das escolas municipais.

Em nível nacional, é preciso que se destaque a recente opção pela utilização do software livre em estabelecimentos públicos federais e em escolas, expressa nas Diretrizes do Comitê Técnico de Implementação de Software Livre, dentre as quais merecem especial atenção a diretriz número sete que determina a opção por "utilizar o software livre como base dos programas de inclusão digital"; o Objetivo G que se propõe a "disseminar a cultura de Software Livre nas escolas e universidades" e finalmente, a Ação Prioritária número nove que consiste em "Desenvolver aplicativos direcionados a projetos educacionais e pedagógicos". (ITI, 2005).

Entretanto, apresar de representarem um avanço no que se refere à lógica de consumo imposta pelo mercado, rompendo com a dependência de pacotes fechados e incentivando o desenvolvimento nacional, é necessário que se aponte a necessidade de realizar ações no sentido de não somente utilizar e colaborar com o desenvolvimento de 
softwares livres, mas, principalmente, assumir sua filosofia como base de ação e de propostas de inclusão, de formação docente e de programas de informática educativa.

Nesta perspectiva, incluir digitalmente é um processo sobretudo de autoria e colaboração, de emissão de significados e sentidos, fazendo da rede um ambiente natural de comunicação, de troca de informações e de construção do conhecimento. Portanto, desvincular Software Livre e sua filosofia de ações de Inclusão Digital, representa, além da incoerência teórico-conceitual já citada, uma ação contrária à opção nacional potencialmente orientada à criação de uma cultura de colaboração, comunicação, exercício da cidadania e democratização do conhecimento.

Desta forma e assumindo a responsabilidade de fomentar a Inclusão Digital em uma perspectiva diferente da tradicional reprodução e passividade inerente a processos de treinamento para a utilização de determinados programas, característica básica das aulas de informática, o Mutirão pela Inclusão Digital sustentava-se sobre as bases da experimentação, da criação, da comunicação, da construção e do exercício da cidadania.

\section{A GÊNESE DO MUTIRÃo PELA INCLUSÃo DigITAL}

É neste contexto que em 2004 o Projeto Mutirão pela Inclusão Digital iniciava suas atividades, aprofundando uma parceria já existente entre o Curso de Ciência da Computação (CCC) e Centro de Referencia em Literatura e Multimeios1 (CRLM), ambos da Universidade de Passo Fundo.

Salienta-se que, mais do que o estabelecimento de uma atividade adicional e conjunta, o Mutirão pela Inclusão Digital representava o necessário e natural imbricamento das concepções e propostas práticas destes dois grupos, dadas as características e demandas da sociedade contemporânea, profundamente modificada pelas TR e carente de propostas de inclusão na perspectiva deste texto.

Assim, o objetivo inicial era o de criar um ambiente onde fosse possível incentivar o desenvolvimento de sujeitos habilitados a ser e estar no Ciberespaço, tendo como público alvo alunos de escolas públicas do Bairro São José, região onde se encontra o Campus Central da Universidade de Passo Fundo.

Tal escolha teve por base alguns importantes elementos: (1) Contemplar a população do referido bairro como forma de reconhecimento e de comprometimento com o desenvolvimento da região onde a UPF está instalada; (2) Facilitar o deslocamento dos alunos até o Laboratório Central de Informática da UPF; e (3) Facilitar o intercâmbio de informações entre Equipe do Mutirão e as escolas envolvidas.

Feita esta primeira definição, estabeleceu-se a necessidade de definir quais e quantas escolas deveriam fazer parte das atividades a serem realizadas, uma vez que se previa a criação de duas turmas com no máximo 20 alunos cada. Para esta decisão foram consideradas a estrutura tecnológica da instituição e a disponibilidade de horários da equipe de voluntários do Mutirão, formada por professores e alunos do CCC. Nesta etapa, optou-se por contemplar as escolas Fundação Educacional do Menor e Benoni Rosado, que naquele semestre não estavam desenvolvendo atividades junto ao CRLM.

Determinadas as escolas, realizou-se um encontro entre a coordenação do Mutirão pela Inclusão Digital, a coordenação da Secretaria de Educação da Prefeitura Municipal de Passo Fundo e as diretoras das referidas escolas, a fim de apresentar o detalhamento e objetivos da experiência. Na oportunidade, decidiu-se que a escolha dos 20 alunos de cada escola ficaria a cargo das direções, sendo condição primeira de seleção a participação prévia do aluno em projetos de exercício da cidadania da escola; que a prefeitura municipal disponibilizaria um ônibus para o translado das crianças; e o número de encontros a serem realizados a partir dos objetivos do projeto.

Em função dos projetos interdisciplinares específicos definidos junto às escolas envolvidas e dos horários de seus alunos, os encontros se desenvolveram em turno V.3 $\mathrm{N}^{\mathrm{o}} 2$, Novembro, 2005 
inverso às aulas, a saber: quintas-feiras pela parte da manhã com as crianças de 1a a 4a séries e nas sextas-feiras à tarde com os alunos da $5 \mathrm{a}$ a $7 \mathrm{a}$ séries.

Os encontros, denominados Oficinas de Informática e Cidadania, eram acompanhados pelo grupo de alunos e professores do CCC e tinham como responsáveis os professores das escolas envolvidas, a medida em que se reconhecia a coresponsabilidade e a importância do envolvimento da escola e de seus professores em iniciativas de Inclusão Digital na perspectiva proposta na experiência.

Durante as oficinas, desenvolviam-se atividades de suporte aos projetos escolares nos quais os alunos estavam envolvidos em suas escolas, configurando-se como matéria-prima, buscando possibilitar uma apropriação crítica e contextualizada das TR e de suas potencialidades, em um processo de crescente domínio das ferramentas de informática. Tais oficinas, em uma lógica contrária à idéia de aulas de informática, estavam organizadas de seguinte maneira:

Conhecimento da tecnologia: Constituiu o primeiro contato com computadores para a maioria dos alunos. Tal módulo utilizou o sistema operacional Linux, e teve por objetivo desenvolver habilidades com o mouse, teclado e janelas através da navegação em sites de interesse comum na Internet;

Durante estes momentos não se propôs nenhuma dinâmica de transmissão de conceitos ou procedimentos técnicos de utilização dos computadores, característica básica de aulas de informática, deixando o grupo livre para, em uma dinâmica de descoberta e experimentação, desenvolver e exercitar habilidades de ordem técnica. Responsáveis pela construção de seus próprios caminhos de aprendizado, alternavam momentos de experimentação individual e de partilha de descobertas com seus colegas. É importante salientar que, ao final do primeiro encontro, os procedimentos básicos de manipulação de janelas e mouse já tinham sido apropriados pelo grupo.

Produção Textual: A partir de das produções nos projetos nos quais estavam envolvidos nas escolas, os alunos aprenderam a utilizar editores de texto e programas de construção de apresentações eletrônicas constantes do pacote OpenOffice, em uma dinâmica de descoberta colaborativa através da troca de experiência com seus colegas;

Sem o intuito de fornecer uma preparação para o mercado de trabalho, o que seria uma incoerência em se considerando a idade dos alunos e as verdadeiras necessidades do mercado, estas oficinas, priorizavam a liberdade em, (re) construir textos previamente desenvolvidos nas escolas, em um processador de textos ou em um programa de construções de apresentações eletrônicas, como proposta de experimentação de momentos de autoria e como forma de socialização de suas descobertas e experiências entre os colegas de escola que não participavam do projeto.

Comunicação na Internet: Uma vez que a primeira oficina já havia proporcionado o contato com a Internet como meio de acesso a informações, este visava propiciar a utilização de ferramentas de busca, criação e utilização de correio eletrônico, bem como de participação em salas de bate-papo e fóruns ${ }^{2}$, privilegiando as características comunicacionais das TR;

Nesta oportunidade observou-se inicialmente uma certa dificuldade, decorrente de uma vivência de passividade e recepção por parte dos alunos em apropriar-se da idéia de que, a partir daqueles equipamentos era possível, não somente acessar e receber informações, mas também, e principalmente, utilizá-lo como forma de comunicação e de troca. Gradativamente, a dimensão de comunicação bidirecional 
das TR foi apropriada pelo grupo que, em uma dinâmica lúdica, enviavam mensagens eletrônicas aos seus colegas e corriam até eles para verificar a chegada da mensagem, alegrando-se caso chegassem a seus destinatários antes da mensagem que enviaram, ficando freqüentemente ansiosos por ler as respostas aos e-mails enviados.

Construção de Páginas na Internet: Esta oficina final buscava possibilitar aos alunos a construção de suas próprias páginas em uma atividade de disponibilização de informações significativas para cada um, em um processo de valorização da própria cultura e de respeito à identidade.

Com o objetivo de completar a vivência de uma cultura de rede, era necessário que não somente se possibilitasse aos alunos momentos de auto-ressignificação em função da interação com e através da rede, mas que estes pudessem de fato, e em um movimento de descoberta do potencial de autoria, modificá-la assumindo-se enquanto nós de uma rede complexa e em constante movimento, utilizando-a como espaço de disponibilização de informações, de expressão de significados e de divulgação de idéias.

Ressalta-se que todos as Oficinas possuíam o objetivo comum de proporcionar aos alunos a possibilidade de assumirem papel de efetivos emissores, rompendo com o paradigma de recepção a que estão submetidos e, desta forma, buscando fomentar o reconhecimento do papel e do espaço de cada um na Sociedade Contemporânea.

Um elemento a ser destacado, e que reforça a urgência e a coerência do conceito de inclusão assumido na proposta, foi a constatação de que a camada social à qual os alunos pertenciam não influenciou no processo do desenvolvimento das habilidades técnicas necessárias para a utilização e manipulação das TR, sendo que o grande diferencial da experiência foi a vivência de um processo horizontal e reticular de autoria e comunicação suportado pelas TR. Em outras palavras, vincular Inclusão Digital simplesmente ao acesso às TR é aprofundar a exclusão social.

\section{A HIPERTEXTUALIDADE DA REDE CRIADA}

Por fim, é possível registrar outras demandas nascidas durante a realização das atividades do Mutirão pela Inclusão Digital, enquanto representação da ampliação do conceito de inclusão proposto neste artigo:

\section{O Kit Escola Livre}

No decorrer dos encontros utilizando o ambiente Linux, verificou-se que, embora não tenha constituído um elemento que pudesse dificultar a interação dos alunos, algumas funcionalidades poderiam ser implementadas no sentido de torna-lo ainda mais intuitivo, amigável e voltado a iniciativas de Inclusão Digital. Assim, a partir desta possibilidade, iniciou-se o processo de geração de uma distribuição Linux para este fim denominada Kit Escola Livre e cuja versão de testes já está disponível para utilização ${ }^{3}$.

Novas oficinas de informática e cidadania

Registram-se também, as outras demandas atendidas ainda no segundo semestre pelo Mutirão pela Inclusão Digital, com destaque às oficinas ministradas a um grupo de alunos surdos que participam da Associação de Pais e Amigos dos Deficientes Auditivos de Passo Fundo; às Oficinas para alunos da Fundação de Atendimento SócioEducativo (FASE); e as oficinas de Software Livre oferecidas no Simpósio de Informática do Planalto Médio de 2004 para professores da rede municipal de ensino, 
reafirmando a idéia de que inclusão digital é, sobretudo, uma ação a ser desenvolvida nos estabelecimentos de ensino.

\section{Compromisso com o avanço do conhecimento gerado}

A fim de que fosse possível resgatar o processo a qualquer momento, refletindo teoricamente sobre a experiência, criou-se um fórum de discussão ${ }^{4}$, onde os envolvidos no projeto registravam suas reflexões e impressões sobre os encontros, constituindo-se em um rico repositório de dados a partir do qual se pode aprofundar a dimensão de análise do processo vivenciado, e principalmente, representa um compromisso com a concepção de inclusão digital baseada na horizontalidade, na participação e na colaboração.

\section{Alguns Nós A CONECTAR}

Como elementos nascidos desta experiência a serem discutidos e ampliados, aponta-se a urgência de se implementar e assumir este novo paradigma de inclusão digital nas escolas como forma de (re) significar a presença crescente das TR, construindo uma informática educativa que, em considerando as características das redes, propicie o desenvolvimento de processos colaborativos de construção do conhecimento e de apropriação crítica e criativa dos recursos tecnológicos em uma perspectiva de exercício da cidadania.

Ainda neste sentido, fica clara a urgência de políticas públicas que, mais do que disponibilizar o acesso e a utilização de software livre, assumam sua filosofia como base para o fortalecimento dos nós da rede complexa composta por Escolas, Universidades, Poder Público e Sociedade, seja no tocante à necessidade de uma formação docente que considere a apropriação crítica e criativa das TR, seja na necessária reflexão e modificação da estrutura linear e hierarquizada das grades curriculares para uma dimensão de currículo em rede.

Por fim, no dia 26 de agosto de 2004 ocorreu a formatura dos alunos participantes como evento simbólico de encerramento desta primeira etapa da experiência, a partir da qual pode-se afirmar que o Mutirão pela Inclusão Digital cumpriu seu papel no sentido de proporcionar momentos que possibilitassem, a partir de momentos de autoria colaborativa onde os envolvidos eram os principais protagonistas do processo, a vivência de experiências lúdico-didáticas na busca de construção de uma cultura colaborativa, baseada no reconhecimento e valorização das diferenças.

\section{Agradecimentos}

À Universidade de Passo Fundo e à Universidade Federal do Rio Grande do Sul enquanto instituições de formação acadêmica e científica do pesquisador, à Fundação de Amparo à Pesquisa do Rio Grande do Sul pelo financiamento de bolsista de iniciação científica, ao Laboratório de Tecnologias Audiovisuais da Universidade de Roma Tre/Itália pela possibilidade de realização de estudos avançados na área de pesquisa e ao Alßan Office pelo apoio para a realização destes estudos através de Programa de bolsas de alto nível da União Européia para América Latina (bolsa nº E04D047495BR).

\footnotetext{
Notas

${ }^{1}$ Para mais informações acessar http://inf.upf.br e http://vitoria.upf.br/ leitura/site/ respectivamente.

${ }^{2}$ Disponível em http://www.upf.tche.br/forum/list.php?f=107. 
${ }^{3}$ Download da versão 0.36, disponível em http://ftp.upf.br/incoming/SoftwareLivre/kit_escola_livre.iso.

${ }^{4}$ Disponível em http://www.upf.br/forum/list.php?f=91.

\section{REFERÊNCIAS}

BRASIL. Ministério de Ciência e Tecnologia. Ganhos com o uso de Software Livre. Disponível em $<$ http://agenciact.mct.gov.br/index.php?action=/content/view\&cod_objeto=17432>. Acesso em: 18 mai. 2005.

ITI. Planejamento Estratégico para implementação de Software Livre. Disponível em < http://www.softwarelivre.gov.br/diretrizes/>. Acesso em: 22 abr. 2005.

LEMOS, A. Cibercultura: Tecnologia e vida social na cultura contemporânea. Porto Alegre : Sulina, 2002, pp. 296.

PROCEMPA. Escolas Municipais a Caminha da Informatização. Disponível em $<$ http://www.procempa.com.br/educ.htm>. Acesso em 17 mai. 2005.

SANTOS, M. Por uma outra Globalização: do pensamento único à consciência universal. São Paulo, Record, 2004, pp. 174.

SERPA, F. Rascunho Digital: Diálogos com Felippe Serpa. Salvador: Udufba, 2004, pp. 320.

SILVEIRA, S.; C, J. Software Livre e Inclusão Digital. Porto Alegre : Conrad, 2003, pp. 339. 